\title{
A Abertura e o Estado Pluralista como Busca de Solução Constitucional ao Problema das "Duas Bolívias"
}

\author{
Salvador Schavelzon (*)
}

\begin{abstract}
Resumo: Esse trabalho faz uma análise do contexto político boliviano atual, à luz da nova ordem aberta com a promulgação da Constituição em fevereiro de 2009, e o começo da sua implementação. A partir da análise do novo texto constitucional, me deterei na consideração das (in)definições no plano da autonomia; da oficialização de línguas indígenas; da economia; da cultura; da justiça comunitária; e da representação política dos povos minoritários. $\mathrm{O}$ artigo é uma apresentação das tentativas pluralistas de reforma política e do complexo processo de acordo político com que estas se depararam. Antes de entrar na análise da nova Constituição, percorrerei o campo das ideias políticas na Bolívia e a imagem local das "duas bolívias" como problema que permite entender o contexto em que a Assembleia Constituinte foi convocada.
\end{abstract}

Palavras-chave: Bolívia, Estado Plurinacional, Constitucionalismo, Evo Morales, Antropologia do Estado.

Abstract: This study examines the current Bolivian political context, considering the new order opened with the promulgation of the Constitution in February 2009, and the beginning of its implementation. In the analysis of the new constitutional text, I will dwell with the account of (in) definitions in the subjects of autonomy, the validation of indigenous languages, economy, culture, communitarian justice, and political representation for minoritarian ethnics groups. The article presents the attempts of a pluralistic political reform and the complex political process that they have encountered. Before entering in the analysis of the new constitution, I will begin exploring the field of political ideas in Bolivia and the local image of the "two Bolivias" as a problem that can lead us to understand the context in which was established the Constituent Assembly.

Keywords: Bolivia, Plurinational State, Constitutionalism, Evo Morales, Anthropology of the State.

(*) Antropólogo, Graduado na Universidade de Buenos Aires, Mestre e Doutorando pela Universidade Federal de Rio de Janeiro (PPGSA e PPGAS).E-mail: schavelzon@gmail.com. Recebido em: 16.1 1.2009 e aceito em: 22.3.2010. 


\section{INTRODUÇÃO: DO DOIS PARA O MÚLTIPLO}

Na Bolívia, muitas coisas aparecem sob o signo da dualidade: Oriente e Ocidente; terras baixas e terras altas; a fórmula de chacha-warmi (homem-mulher) na tradição de governo aimará; e a ideia das “duas bolívias” frequentemente mobilizada no discurso político boliviano. Ocuparei-me com a continuação desse problema das “duas bolívias”, que consiste na leitura da realidade boliviana com ênfase na fratura e na divisão irreconciliável. Esse problema apareceu formulado com claridade pelo indianismo de Felipe Quispe, protagonista de bloqueios na região do altiplano entre 2000 e 2005. Ele mobilizava uma política da memória histórica das rebeliões indígenas e do enfrentamento entre o país dos índios e o dos espanhóis, atualizado na época republicana como o país dos índios, e dos mestiços. Muitas vozes provindas do espectro político oposto aos camponeses indígenas, também utilizam a imagem das "duas bolívias" para criticar o que entendem como atropelo das libertais individuais por parte do governo de indígenas e sindicatos rurais. A ameaça da anarquia que muitos republicanos sentem quando se fala em pluralismo abre as portas para as formas de governo e de justiça indígenas.

A imagem da oposição de “duas bolívias”, no entanto, também deriva da cosmologia andina em imagens do encontro, da mistura e da combinação. A personagem híbrida do Pepino no carnaval representa a ambiguidade, e os que entendem de filosofia andina destacam a dualidade e a complementaridade como princípio onipresente (ESTERMANN, 1998), junto com a reciprocidade, base da economia das comunidades andinas históricas e, até hoje, presente nos Andes (TEMPLE, 1995). Essa é outra chave de leitura da realidade política que não parte da fratura, mas do encontro e do diálogo. Filemón Escóbar, um dos fundadores do MAS (Movimiento al Socialisto) e mentor de Evo Morales, agora distanciado e crítico, é um dos que aludem à cosmologia andina para pensar na política atual. Em recente livro (2008), ele defende essa visão que busca, na complementaridade, um contraponto da confrontação que ele encontra na política do atual governo boliviano e da oposição.

Evo Morales (empossado em janeiro de 2006) também pode ser lido à luz do dois. Os primeiros três anos do seu governo passaram entre a busca do consenso e o enfrentamento entre dois projetos políticos. A política do país aparece marcada pelo Dois com um cenário político sumamente polarizado entre os setores regionais dos governos departamentais do leste, com gás, soja e petróleo, e o governo dos camponeses e setores de esquerda com força eleitoral na parte ocidental do país, mais populosa e também mais pobre. Essa oposição se expressou entre agosto de 2006 e dezembro de 2007, durante a Assembleia Constituinte, que será o eixo da análise neste texto. Durante meses, todos os esforços em redigir uma Constituição de consenso fracassaram. Só depois do ponto mais álgido nos enfrentamentos entre governo central e as regiões de Oriente (em setembro 2008), o governo conseguiu conformar uma mesa de diálogo e viabilizar um acordo com a oposição no congresso nacional, para que em janeiro de 2009 os bolivianos votem a aprovação da nova Carta Magna, promulgada, finalmente, em fevereiro de 2009.

O desenlace com aprovação de nova Constituição pode ser lido como uma imposição do projeto de Evo Morales, depois de ter ganhado no referendo revocatório com o 67,4\% dos votos. Não seria um encontro de diferentes, mas uma imposição. Essa é a leitura da 
oposição. Mas na leitura do texto constitucional aprovado que apresentarei a continuação, é evidente que o resultado final não foi o que o MAS (partido de governo) propôs, e sim um texto que, além da proposta do governo, inclui a revisão do texto realizada no Congresso por parlamentares da oposição e com mudanças propostas pelos prefeitos (governadores) das regiões opositoras. Nesse sentido, o problema das "duas bolívias" teria tido no processo constituinte uma resolução, fruto do acordo, como podemos ver nos conceitos centrais estabelecidos no primeiro artículo:

Artículo 1. Bolivia se constituye en un Estado Unitario Social de Derecho Plurinacional Comunitario, libre, independiente, soberano, democrático, intercultural, descentralizado y con autonomías. Bolivia se funda en la pluralidad y el pluralismo político, económico, jurídico, cultural y linguístico, dentro del proceso integrador del país.

No primeiro artigo da constituição, demandas centrais da oposição foram incluídas como o reclamo das autonomias e a ideia de Estado Social de Direito. Mas o encontro de diferenças vai além e aparece na opção pela multiplicidade, que pode ser pensada como solução política ao problema das “duas bolívias", e que deve ser entendida não só como encontro do governo e a oposição, mas também do encontro dos diversos setores políticos indígenas, camponeses, mineiros, classe média urbana, etc, que formam parte da base do partido de governo. A opção pelo pluralismo é a proposta que visa a inclusão dos 36 povos indígenas considerados excluídos do poder político e econômico, por causa da discriminação e desvalorização cultural. A ideia de complementaridade de sistemas civilizacionais diferentes e do pluralismo, marca a inclusão dos diferentes povos indígenas a partir de reformas que tentam agregar um modelo de Estado alternativo ao "um”; sendo o "um”, no mundo político boliviano, a nação boliviana monocultural, falante de espanhol e de religião católica, a que, agora, se oporia ao Estado Plurinacional conformados por muitos povos e nações. Alguns trabalhos que podem ser citados como antecedentes dessas reformas estatais feitas da perspectiva pluralista são os do Grupo Comuna, cujos membros foram ativos participantes do processo constituinte, desde a análise intelectual ou a prática política (GARCIA LINERA; GUTIERREZ; PRADA; TAPIA; 2000; GARCIA LINERA; TAPIA; PRADA, 2007). A complementaridade e o dois, assim, dá lugar não só a duas, mas à multiplicidade de muitas bolívias que compõem o Estado Plurinacional, e que busca, também, se afastar do multiculturalismo incluído no Estado boliviano em reformas da década de 90, entendido como a inclusão subordinada da diferença e, portanto, uma nova versão do Dois que separa indígenas como cidadãos de segunda classe.

No processo constituinte, a solução pluralista que permitia incluir as diferenças não só políticas mas também "civilizacionais" e cosmológicas, não conformava à oposição que, em lugar de um pluralismo combinado com um governo centralizado, exigia poder político para as regiões e descentralização, mas a partir de uma lógica republicana e liberal tradicional marcada pela imagem da homogeneidade cultural, com o espanhol, por exemplo, como única língua oficial. A busca de um modelo de Estado que evitasse a fratura, então, não consistiu só no pluralismo do Estado Plurinacional Comunitário proposto pelo MAS, mas também na inclusão do reclamo da oposição. Além da inclusão dos conceitos citados, originalmente fora do projeto do MAS e presente nos primeiros rascunhos de Constituição da oposição, devia se construir uma ordem constitucional equilibrada. Nesse sentido, no 
primeiro artículo, também encontramos compromisso entre forças centrípetas e centrífugas na combinação do Estado Unitário, com a descentralização e a plurinacionalidade, que remite, antes, a formas políticas de tipo confederativo.

Na continuação, apresentarei algumas notas que surgem de uma pesquisa etnográfica do processo constituinte boliviano e que visam aportar elementos para entender o movimento contínuo - na realidade política boliviana - entre as relações que citamos acima: a unidade, a diversidade, a oposição, o acordo, a pluralidade. Esses movimentos marcam a atual fase da política boliviana no momento pós-constituinte em que devem ser implementadas as leis que regulamentam a constituição. Esse trabalho tem como centro o cenário parlamentar onde a marca da oposição entre “duas bolívias” se reedita em vários debates trazidos pela nova Constituição.

\section{A ambivalência dos Significados no Estado boliviano e no governo de Evo Morales}

Para pensar no sentido das reformais estatais abertas trazidas pela nova constituição, é interessante a ambivalência presente nos atos de governo e na própria direção do projeto político liderado por Evo Morales. O ubíquo lugar do indígena e a mistura de elementos ideológicos e identitários heterogêneos fazem do processo político boliviano um processo original e difícil de classificar. Para analisar o processo, é bom começar por tentar entender o governo Morales, que controlava a maioria na Assembleia Constituinte.

Em relação ao Estado, o sentido da atual administração não é unívoco: de um lado, a nova Constituição e gestão de governo parecem potenciar o componente da "descolonização" apoiando o mundo indígena em detrimento do Estado, foco colonial desta crítica. O processo político atual não pode ser analisado, nesse sentido, a partir das tradições do mundo das comunidades rurais de onde provém o núcleo do MAS e o maior apoio eleitoral. Nesse sentido, um processo de desestruturação da república teria se iniciado com a chegada dos campesinos e indígenas no Estado e se fortalecido com a aprovação da nova Constituição. Por outro lado, porém, a reforçada legitimidade da autoridade estatal na atual fase política, junto com os ingressos mais altos da história da Bolívia no tesouro estatal e dos municípios - por causa do gás - poderia significar uma revitalização da república que, ela primeira vez, aparece presente nas comunidades com um Estado que, longe de ser ameaçado, se mostra agora mais fortalecido. A posição intermediária e combinatória, seria a ideia de Estado descolonizador que abraça o pluralismo para ser, pela primeira vez, um Estado de todos os bolivianos.

Mas a ambiguidade do Estado não é apenas responsabilidade do governo de Evo Morales. A própria eficácia e viabilidade do Estado é, frequentemente, contestada na Bolívia. A partir da importância do mundo rural comunitário, é comum ouvir na Bolívia que não existe nem Estado nem relações de produção capitalistas bem estabelecidas. Luis Tapia (2002) fala da "condição multisocietal” da Bolívia, que combina o capitalismo moderno com modos não capitalistas nas comunidades e que, talvez, possa ser elemento fundamental no assunto da questionada estatalidade. Essa fragilidade institucional se evidencia na 
negação do próprio nome do país por parte dos aimarás que rejeitam a homenagem a Simón Bolivar, que os combateu, e que expressam também um sentimento que muitos vêm como porto-nacional. E a fragilidade também é clara, se observarmos o deficiente controle e expansão sobre o território. Na Bolívia, a rede de caminhos é descontínua e precária, a presença de autoridades judiciais é escassa e existem vários problemas de limites entre municípios, e até entre departamentos. Bolívia perdeu território de todos os lados (de Chile, Brasil, Paraguai, Argentina); e também gerou uma consistente fama de terra sem lei, onde poderiam iniciar a sua vida criminais e bandidos prófugos do mundo todo. $\mathrm{O}$ aumento da demanda pela autonomia da região da Meia Lua não seria mais do que a confirmação desta debilidade do Estado, com recorde regional de golpes de Estado, numa região onde os golpes não foram poucos.

O perfil do Evo Morales, também deixa ver a fraqueza do Estado. A ambivalência aparece no jogo entre uma posição de autoridade estatal, combinada com a crítica às instituições republicanas por parte de um presidente que, durante anos, foi alvo da repressão estatal quando dirigia os sindicatos de produtores de coca e foi expulso do congresso em 2002 depois de ser eleito deputado; acusado de narcotraficante e terrorista. Nos hábitos políticos, de vestimenta e discurso, Evo Morales, cotidianamente, parece mostrar que é de fora do Estado, ou pelo menos de fora do Estado tal como era desde a fundação da Bolívia. Sem deixar o lugar de alocução como autoridade dos bolivianos, Evo Morales mantém o lugar de líder sindical, participando de passeatas, sendo eleito autoridade dos cocaleros e em suas opiniões, como quando expressou que ele fazia as coisas e só depois chamava os advogados para consertar (SIVAK, 2008).

No mundo intelectual e político, existem várias expressões contraestatais e comunitaristas inspiradas pelo mundo indígena. No plano do pensamento político, pode ser mencionado Fausto Reinaga (1991) precursor do indianismo, com a ideia de revolução indígena contra a república nacionalista, e também de esquerda. Na atualidade, os trabalhos de Raúl Prada (2008) apresentam a comunidade local andina (ayllu) como uma forma arcaica contra estatal, que preexiste, inclusive, ao Estado dos Incas e que se encontra em guerra contínua contra um Estado. Longe da imagem estatal das comunidades que foram parte do império Inca, nesta análise, a comunidade aparece afastada de um Estado que sempre tentou reduzi-la e controlá-la. Para Raúl Prada, representante constituinte do MAS na Assembleia, o ayllu andino é atual e suas formas ultrapassam o âmbito rural das comunidades, tendo aparecido, por exemplo, nas redes de sindicatos que realizaram importantes protestos no período 2000-2005.

Mas, ao mesmo tempo, a presença da comunidade na política estatal sai, às vezes, do primeiro plano e o lugar de Evo Morales é, também, o do primeiro presidente, em muito tempo, com possibilidades reais de converter a Bolívia em um "verdadeiro Estado", como grande administrador das riquezas em hidrocarbonetos descobertas a partir de 1997, que, após o decreto de nacionalização, permitiu um considerável aumento dos ingressos estatais. Esse é o Evo Morales que, longe do perfil comunitarista, personifica fortemente o papel de desenvolvimentista, modernizador e líder de um Estado, pela primeira vez, viável e sem déficit. Evo Morales poderia ser considerado, sob essa perspectiva, como o responsável de erguer um Estado legítimo que estende seus monopólios como nunca antes nessas terras. 
A elite boliviana parece ter raciocinado assim, quando antes das eleições que levaram Morales à presidência dizia, num comentário irônico popularizado, que votaria por Evo Morales como única forma de que terminassem os bloqueios nas estradas. Seria o Estado dos movimentos sociais o único Estado possível na Bolívia.

E a pergunta de pesquisa que se abre nesse ponto é se uma ampliação democrática em termos de novos atores que acessam ao sistema político significa uma mudança no tipo de Estado e de representação política. A resposta deve buscar até que ponto o novo Estado Plurinacional é uma revolução política, até que ponto mudou a ênfase da economia de mercado para a comunidade e até que ponto as mudanças jurídicas pluralistas caracterizam o Estado boliviano como diferente. Lendo uma proposta de reforma estatal do atual vice-presidente (GARCÍA LINERA, 2005), publicada pouco antes do seu triunfo eleitoral junto a Evo Morales, já era possível encontrar uma dupla leitura do sentido político do novo Estado. A proposta que ele fundamentava, de autonomias indígenas e um Estado Multinacional dizia que uma verdadeira república poderia ser só — na Bolívia — uma democracia pluricultural e multiétnica. Nesse sentido, era citado o filósofo político Will Kymlicka (1996), referência na defesa dos direitos coletivos como acordes com o marco do liberalismo. Ao mesmo tempo, no mesmo trabalho do vice-presidente, se visava potenciar o autogoverno aimará e os modos políticos comunitários próprios das cosmovisões indígenas, em direto desafio à república liberal do Estado moderno.

Essa ambiguidade nas interpretações sobre a força do Estado boliviano parecem não ter resolução em apenas uma direção. E acho que essa é uma marca do próprio Estado e do atual processo político boliviano. Talvez seja aí mesmo, na dualidade, ou na dupla face da ação estatal, onde radica a força política e governabilidade do MAS, assim como do imaginário político que as fundamenta. E veremos na continuação como essa flexibilidade conceitual alcança diversas áreas como a definição identitária e política do próprio Evo Morales e seu governo.

Se ouvimos, de um lado, que o governo de Evo Morales é considerado o primeiro governo das maiorias indígenas, por outro lado se afirma que o Estado do MAS não seria indígena nem comunitário, começando porque o próprio Evo Morales não seria "realmente" um indígena, e utilizaria esse rótulo apenas como estratégia política. Não sendo indígena, Evo Morales aparece, para alguns, como nacionalista. A importância da associação à nação boliviana, antes do que à etnia aimará, afasta o imaginário político do Estado indígena própria de visões superficiais sobre a Bolívia, no entanto, às vezes, também alimentada desde o discurso do governo. Elementos como a aliança estratégica com os militares, a nacionalização de empresas, o discurso da unidade nacional na frente de tudo e a utilização da categoria indígena de modo genérico, e não referente a etnias específicas, fortalece essa classificação. De qualquer modo, o assunto da identidade política de Evo Morales não é fechado. Ele se reconhece como indígena e fala como representante dos indígenas que entraram pela primeira vez no governo. Fora a questão da identidade étnica, também sua identidade política é controversa. Expressou algumas vezes acreditar em deus, quando o assunto da religião entrou na campanha pela nova Constituição, por exemplo, e também se definiu como marxista-leninista quando defendia a incorporação de Cuba à Organização dos Estados Americanos — OEA. Manifestou querer o socialismo comunitário, é aliado de 
Cuba e Venezuela, mas também reivindica a luta étnica, e não de classe, dos indígenas e defende o desenvolvimentismo industrializador dentro do marco do capitalismo.

Olhando para as ações de governo, as marcadas pelo nacionalismo e o estatismo são das mais importantes e com maior destaque no discurso do governo. Mas políticas multiculturais na educação, por exemplo, e o marco da nova Constituição, também dão destaque ao componente indígena no atual processo político. A ideia do indígena, além disso, aparece associado à maioria da população que assim se reconhece (62\% no último Censo de 2001), colocando-a como raro caso em que os reclamos de direitos indígenas não aparecem ligados a minorias nem separado do discurso nacionalista boliviano.

Prova da controvérsia a respeito da identidade é a proveniência multiplicidade de localização das críticas. O indigenismo aimará nega o caráter indígena desse governo, critica a sua composição majoritariamente branca ou mestiça, e o acusa de traição dos indígenas por dar continuidade à república colonial (ver por exemplo a periódico Pukara ${ }^{(1)}$ ). Também o ex-vice-presidente aymará na década 90, Víctor Hugo Cárdenas, questionava a identidade indígena de Morales, por não falar línguas e ser solteiro. E ouvimos também críticas desde a posição da soberania nacional, que considera que as nacionalizações não foram realizadas de modo consistente e que as reformas do pluralismo cultural, trazem riscos para a defesa do interesse nacional. Nesse sentido, podemos citar as críticas ao Estado Plurinacional do ex-ministro de hidrocarbonetos de Evo Morales, Andrés Solís Rada (2009), que pergunta-se: "Evo não nota que um país estilhaçado não pode se defender frente às transnacionais?” acusando a “política desagregadora do 'gonismo', à qual se uniu ao MAS ao estabelecer o reconhecimento constitucional a 36 nações indígenas, as quais pretenderão cobrar impostos pela água e pelos gasodutos que cruzem seus ‘territórios', significará uma espécie de retorno à Idade Média, que fraturará o país e provocará enfrentamentos fratricidas”.

Mas se as críticas vêm de toda direção, também é verdade que os setores incluídos no atual governo e que confluíram no MAS também é amplo. Talvez, sem uma aliança dessas características seria inexplicável a fortaleza eleitoral e política de Evo Morales, e a forma em que conseguiu juntar, no mesmo projeto, os principais reclamos do período de instabilidade política anterior. Essa heterogeneidade era visível na composição do conjunto de representantes do MAS eleitos para a Assembleia Constituinte. É o processo constituinte um bom espaço para avaliar essa capacidade do projeto político liderado por Evo Morales para incluir e apresentar uma solução para o problema das “duas bolívias", ao que fizemos referência mais acima, e que diz respeito diretamente à questão indígena. Vejamos, então, a continuação como essa apertura, flexibilidade e ambiguidade na definição política estratêgica e identitária do governo, se expressou no processo constituinte.

\section{Processo Constituinte e nova Constituição}

Além de uma ambiguidade que pode ser entendida como reflexo da ampla base ideológica do MAS, a ambiguidade aparece como produto de um processo constituinte que

(1) Disponível em: <http://www.periodicopukara.com/>. 
foi desenvolvido num contexto de conflito político em que toda afirmação do partido de governo era contestada por uma oposição que o impedia chegar nos dois terços. Prevendo essa situação, o partido de governo tentou, sem sucesso, aprovar um regulamento de votações que lhe permitisse tomar decisões por maioria absoluta. Mas a oposição se impôs e a busca dos dois terços torturaram o MAS durante todo o processo. O conflito na Assembleia Constituinte também veio de fora, com protestos na cidade de Sucre pela volta dos poderes de governo - trasladados para La Paz mais de cem anos atrás - que impediram o funcionamento das sessões plenárias. Os representantes de Sucre, aliados aos representantes opositores da Meia Lua (sul e leste do país), apostaram a que a Assembleia terminasse sem resultados e não contribuíram na busca de um texto de consenso que conseguisse dois terços. Sem poder convocar sessões nem conseguir dois terços, a Assembleia concluiu, fora da sua sede oficial, com um texto elaborado apenas pelo MAS e com poucas possibilidades de passar pelo congresso, onde a oposição devia dar seus votos, que — também por dois terços - seja convocado o referendo de aprovação da nova Constituição.

Mas, finalmente, o governo saiu vitorioso. Depois de dez meses de conflito político nas regiões e sem o diálogo com o qual o governo buscava viabilizar a aprovação do texto constituinte, Evo Morales se impôs num referendo com 67,4\% dos votos — que, paradoxalmente, tinha sido chamado pela oposição - e tudo começou a se encaminhar com o estabelecimento da mesa de diálogo e o posterior acordo no congresso que convocou ao referendo constituinte. O custo para o governo foi aceitar mudanças no texto aprovado na Assembleia, incluindo demandas da oposição na versão final da Constituição. Depois de uma campanha que voltou a polarizar o cenário político na Bolívia, a nova constituição foi aprovada e promulgada em fevereiro de 2009. O processo constituinte, no entanto, se estende a dezembro de 2009 com a eleição de representantes para o novo parlamento plurinacional, e a reeleição de Evo Morales.

O desenvolvimento da Assembleia, naquele contexto de conflito, deu lugar a um tex to não homogêneo, que inclui o encontro de distintas visões de país e interesses diferentes. Assim, no novo texto encontramos: acordos, pontos intermediários, contradições e afirmações que vão em distinta direção. Assim, por exemplo, se declara o fim do latifúndio, colocando um limite de cinco mil hectares, mas se acrescenta que isso afetará as propriedades futuras e não as já existentes. Também, encontramos no preâmbulo da nova Constituição uma declaração em que se afirma a superação do Estado Republicano, mas nas negociações do Congresso que possibilitaram a convocatória ao referendo, se reintroduziu o termo República e um sem número de recortes às definições iniciais aprovadas pelo MAS, meses antes.

O novo texto significou decepção para alguns setores sociais, ao tempo, que para outros, um avanço que posterga as definições para o futuro, mas não fecha as portas para as mesmas. Na continuação percorrerei alguns dos temas centrais que atravessaram o processo constituinte, e a sua resolução aberta ou negociada que permitem medir a importância da flexibilidade, a dualidade, a multiplicidade e a indefinição na política do Estado boliviano.

Para os assessores do MAS na Assembleia Constituinte, a peça mais importante do novo texto era o caráter Plurinacional do Estado. Eles explicavam que seria um aporte ao constitucionalismo a nível mundial, com uma inédita combinação do social, do liberal e do 
comunitário. Segundo a equipe de assessores, a nova Constituição combina o melhor dos constitucionalismos francês de 1789, mexicano de 1917 e soviético de 1935. Mas é difícil ir além na explicação de como se desenvolve esse novo modelo. O caráter Plurinacional (e comunitário) do Estado era caracterizado por uma abrangência, falta de definição e de leitura unívoca que o limitava, para muitos, a um caráter declarativo com poucas implicações reais e que só a partir de futuras definições poderia chegar a ser desenvolvido. Se bem é verdade que o conflito com a oposição contribuiu a essa indefinição, a mesma tinha também outros motivos.

O Estado Plurinacional, às vezes, refere-se aos 36 povos e nações indígenas reconhecidos na Bolívia, cujas línguas são listadas na nova Constituição e obtêm reconhecimento oficial, embora numa cláusula transitória se posterga a implementação do seu uso na administração do Estado à normativa futura. Nesse sentido de Plurinacional, o Estado republicano daria lugar a uma confederação de povos que teriam participação direta no Estado, visto como pluralidade de cosmologias, instituições políticas e línguas em plano de igualdade. Outra leitura do Plurinacional é a de um Estado Unitário, que mantém a forma republicana, mas que inclui no aparelho governamental o povo das cidades e do campo, descendentes das culturas originárias, mas já não necessariamente com uma identidade étnica ou modo de vida diferente. São as duas leituras do indígena que vimos acima. E são duas formas de resolver o problema das “duas bolívias”: ora para o lado da unidade, ora para o da multiplicidade.

Na Assembleia Constituinte, a discussão da identidade apareceu com força na definição do Povo Boliviano e do sujeito-chave de "nações e povos indígenas originário campesinos" presente em todo o texto e destinatário de vários direitos especiais. Na definição dessa categoria, os distintos setores sociais presentes entre os representantes na Constituinte reclamavam ser incluídos. Assim se discutia se a definição utilizaria critérios de classe social ou culturais, e se os sujeitos seriam englobados ou definidos por extenso. Alguns campesinos exigiam não ser separados dos indígenas originários, porque era assim que também eles se reconheciam; mas outros preferiam manter uma identidade distintiva, do mesmo modo que os afrobolivianos e as mulheres, que queriam ser mencionados de forma separada na definição de "povo boliviano", categoria introduzida como novo proprietário dos recursos naturais, desbancando desse lugar ao Estado. A definição da categoria "povo boliviano" sofreu uma modificação com a revisão do Congresso, em outubro de 2008, que reintroduziu nesse artigo o conceito de nação, que tinha saído na formulação do MAS na Assembleia Constituinte. $\mathrm{O}$ assunto pode ser analisado em relação à própria falta de definição de Evo Morales e seu governo a respeito à identidade do projeto político. A definição de consenso foi abrangente:

Artículo 3. La nación boliviana está conformada por la totalidad de las bolivianas y los bolivianos, las naciones y pueblos indígena originario campesinos, y las comunidades interculturales y afrobolivianas que en conjunto constituyen el pueblo boliviano.

Mas a ideia de "nações e povos indígena originário campesinos", de consenso entre as organizações sociais, trouxe desconfiança na oposição que pensava que não só as minorias étnicas, mas também qualquer campesino na Bolívia que fosse descendente de quíchua ou 
aimará, exigiria direitos especiais. Vários controles foram incluídos no texto para evitar essa interpretação, mas a oposição continuaria criticando que alguns sujeitos sejam definidos explicitamente. A definição de quem é indígena na Bolívia continua em aberto, porque é uma questão impossível de definir por lei, mas também porque as organizações sociais conseguiram, politicamente, que o conceito não se fechasse. O seguinte artículo reconhece direitos presentes na Declaração das Nações Unidas sobre povos indígenas, mas traz controvérsia na Bolívia, pela dificuldade de definir quem é indígena e quem não é, ou melhor, pela possibilidade de que um percentual alto da população seja assim reconhecido:

Artículo 2. Dada la existencia precolonial de las naciones y pueblos indígena originario campesinos y su dominio ancestral sobre sus territorios, se garantiza su libre determinación en el marco de la unidad del Estado, que consiste en su derecho a la autonomía, al autogobierno, a su cultura, al reconocimiento de sus instituciones y a la consolidación de sus entidades territoriales, conforme a esta Constitución y la ley.

Para a oposição, esse artículo significa direitos desiguais entre os indígenas e os não indígenas. Para o governo, é justiça com os, até agora, excluídos do Estado. Fica em aberto a leitura mais restrita que limita sua aplicação a comunidades isoladas e com homogeneidade linguística e cultural, ou que a considera aplicável a populações resultantes do contato contínuo entre quíchuas, aimarás e mestiços, com uma circulação contínua entre territórios, campo e cidade, e que envolve também as comunidades campesinas organizadas em sindicatos no século XX. A definição ampla das "nações e povos", de modo igual que a indefinição da identidade política, abre um leque de possibilidades que são as que dão forma à política boliviana, tanto nas terras baixas quanto nos Andes. O assunto diz respeito, também, ao caráter não minoritário dos povos indígenas na Bolívia.

Para analisar o Estado Plurinacional, podemos explorar as mudanças a respeito aos regimes político, econômico, jurídico, cultural e linguístico, entre outros, em que o caráter Plurinacional aparece desenvolvido. É nesses assuntos nos quais vemos que as "duas bolívias”, se encontram, enfrentam, ou abrem à pluralidade de formas sociais. Em cada tema nos quais encontramos distintas mãos constituintes (às vezes dando conta de tensões internas do próprio MAS) e, também, uma resolução aberta à futura definição. Trata-se, no político, da inclusão de circunscrições legislativas especiais para indígenas; no econômico, do reconhecimento de uma economia plural; no jurídico, da institucionalização da justiça comunitária e do Tribunal Constitucional Plurinacional; no cultural, do respeito autonômico das formas tradicionais e do reconhecimento de direitos coletivos; e no linguístico, da oficialização das línguas.

Um dos primeiros debates posteriores à aprovação da nova Constituição foi o projeto de lei eleitoral do governo no qual, no texto saído da comissão parlamentar, se incluíam 14 circunscrições especiais indígenas, para um total de 135 parlamentares. Trata-se de deputados que serão eleitos nas zonas rurais de cada departamento e que se estabelece, especificamente, para cada jurisdição, de quais etnias deverão ser originários. As 14 circunscrições desenvolvem um dos artigos da nova Constituição que estipulava a representação de minorias. E é um dos primeiros assuntos com os quais a nova Constituição começou a ser implementada. Assim é, também, um dos pontos onde encontramos contradição e apertura na redação da Constituição e nas suas interpretações. 
A representação direta era uma das exigências das organizações indígenas na Assembleia. Se o Estado Plurinacional reconhecia 36 nações, estas deviam ter participação no parlamento nacional, modificando, assim, o modelo republicano e liberal clássico de governo que - nas fundamentações do MAS - as excluiu desde a fundação da república. No art. 146 da nova Constituição — correspondente à composição da Assembleia Legislativa Plurinacional — se estabelece que estas circunscrições indígena originário campesinas reger--se-ão pelo princípio de densidade populacional da cada departamento. Estas não deverão transcender os limites departamentais, serão somente na área rural e quando estes povos e nações forem minoria populacional. Com estas definições, a representação direta não abarcaria as nações indígenas que são majoritárias em seus territórios (os quíchuas e os aimarás das terras altas) e que se supõe que possam eleger representantes por voto universal em circunscrições normais.

Mas as distintas interpretações sobre esse tema têm bastante base para divergir, uma vez que o art. 147 da nova Constituição contradiz o anterior, mencionado acima. Depois de ter tratado o tema das circunscrições especiais indígenas, um novo artigo volta a se referir ao assunto e estabelece que "a lei determinará as circunscrições especiais indígena originário campesinas, onde não deverão ser considerados como critérios condicionantes, nem a densidade populacional, nem a continuidade geográfica”. O critério de densidade populacional é vetado no art. 147 e estabelecido como princípio diretor no art. 146.

Segundo um dos protagonistas do acordo (BORTH, 2008), a contradição se deve a um erro, devido à falta de tempo e de uma comissão de concordância que revisasse o texto modificado no acordo no Congresso. Para outros ${ }^{(2)}$, não é uma contradição, mas um elemento que serve aos povos para exigir distintos tipos de representação, não necessariamente vinculados ao seu caráter minoritário, conforme a baixa densidade populacional. Como em outros temas, a potencialidade do Estado Plurinacional define-se no campo da política, na elaboração das leis que implementam a Constituição e, portanto, na implementação das mesmas em um processo sem fim.

\section{ECONOMIA, JUSTIÇA E LÍNGUAS}

Outro exemplo dos pontos da nova Constituição que se vinculam ao caráter Plurinacional é o do modelo econômico plural que busca utilizar ferramentas do Estado para viabilizar métodos econômicos insignificantes em termos de capital e economia de mercado, mas que envolvem na Bolívia $83 \%$ da população. Isto busca expressar a formação social da Bolívia que René Zavaleta descreveu como “abigarrada” (complexa, em tradução aproximada) e com a ideia de "capitalismo andino" de que falava o atual vice-presidente na campanha para a presidência de 2005. Segundo aquela proposta, os excedentes da economia de mercado seriam aplicados no desenvolvimento da pequena economia urbana mercantil, da economia doméstica campesina e também nas formas econômicas dos povos amazônicos.

(2) Adolfo Mendoza, assessor técnico da organização de indígenas das terras altas, em conversa privada. Y Albó (2009). 
Trata-se da implementação, no nível econômico, do que também se postula para o nível linguístico, da justiça, das formas políticas etc.; e leva para o plano do econômico a proposta pluralista do MAS na constituinte para a resolução e encontro entre as "duas bolívias”:

Artículo 306. [...] II. La economía plural está constituida por las formas de organización económica comunitaria, estatal, privada y social cooperativa. [...]

III. La economía plural articula las diferentes formas de organización económica sobre los principios de complementariedad, reciprocidad, solidaridad, redistribución, igualdad, seguridad jurídica, sustentabilidad, equilibrio, justicia y transparencia. La economía social y comunitaria complementará el interés individual con el vivir bien colectivo.[ ...]

Artículo 31 1. I. Todas las formas de organización económica establecidas en esta Constitución gozarán de igualdad jurídica ante la ley. [...]

Segundo uma das assessoras do MAS para temas econômicos na Assembleia Constituinte (MORALES, 2008, p. 26), o reconhecimento da economia social cooperativa, na nova Constituição, tem a ver com a lógica em que foi redigido o texto pela qual "se orienta claramente a conseguir a visibilidade de setores e temáticas até agora ignorados ou invisibilizados por definições de natureza 'neutra' ou de definições mais gerais. Em toda a redação, incluem-se setores e temas que, de uma perspectiva rigorosa com os conceitos, não deveriam ser incluídos por estarem já incorporados dentro de um conceito geral, mais abarcador”, ela fazia referencia à inclusão de distintas economias de modo igual à inclusão dos "indígenas originário campesinos” na definição abrangente de povo boliviano.

$\mathrm{Na}$ nova Constituição, o pluralismo também alcançou o tema da justiça. E, nesse assunto, encontramos de novo o encontro das "duas bolívias”, que aparecem no encontro entre a justiça comunitária-indígena com a justiça “ordinária” do Estado; e, também, o múltiplo, com o reconhecimento do pluralismo jurídico como base da justiça unitária do Estado Plurinacional. Como em outros temas, também nos artículos sobre Justiça, encontramos indefinição, apertura e contradições.

De um lado, a justiça indígena queda reconhecida pela nova Constituição. No primeiro artículo se declara o pluralismo jurídico; no segundo, é reconhecido o direito à autonomia, ao autogoverno e às instituições próprias, como vimos. Um capítulo especial da nova Constituição é dedicado à jurisdição indígena. Nos seguintes artículos se desenvolve esses direitos:

Artículo 178. [ ...] II. La jurisdicción ordinaria y la jurisdicción indígena originario campesina gozarán de igual jerarquía. [...]

Artículo 190. I. Las naciones y pueblos indígena originario campesinos ejercerán sus funciones jurisdiccionales y de competencia a través de sus autoridades, y aplicarán sus principios, valores culturales, normas y procedimientos propios.

No entanto, na versão definitiva - produto do acordo com a oposição — foram eliminadas frases importantes que iam na direção de garantir a autonomia da justiça das 
comunidades, por exemplo, as que afirmavam que a jurisdição indígena decidiria de forma definitiva, que as suas decisões não poderiam ser revisadas pela jurisdição ordinária, e que seriam executadas em forma direta. Além disso, se acrescentaram cláusulas de controle da justiça indígena como com a explicitação do direito de defesa, que não aparece na justiça comunitária do modo que o faz na ordinária; ou que a jurisdição indígena só seria válida para os membros dos povos originários, e não para quem cometesse delitos neles, como a proposta inicial do MAS habilitava. Assim, se introduziam controles fundamentados propostos pelos críticos à Justiça comunitária, temerosos numa generalização das práticas jurídicas não estatais.

Apesar de, expressamente, definir a igualdade hierárquica entre a justiça comunitária e a ordinária, em outros artículos, ficava clara a subordinação a respeito da justiça estatal. Assim, por exemplo, nos tribunais superiores se estimula a participação de indígenas, mas em proporção minoritária, além de exigir formação acadêmica em direito estatal, limitando, assim, a participação de autoridades comunitárias formadas em outros tipos de tradições jurídicas. A resolução, no entanto, fica postergada para as discussões da lei que implementará a relação entre as diferentes justiças, ou, talvez, para a disputa política sobre a autonomia indígena em cada caso em que a justiça ordinária procure intervir.

Como já adiantei, outro tema em que é possível encontrar falta de definição é no que diz respeito ao uso de línguas originárias como obrigação para os servidores públicos. Como em outros assuntos importantes do processo constituinte (recursos naturais, concessões mineiras e florestais, terra), o avanço nos assuntos — do ponto de vista de governo, ONG, setores sociais — é, depois, aminorado com cláusulas que limitam, postergam ou resignificam os conceitos. Veja-se, por exemplo:

Artículo 234. Para acceder al desempeño de funciones públicas se requiere: [...] 7. Hablar al menos dos idiomas oficiales del país.

Cláusula transitoria Décima. El requisito de hablar al menos dos idiomas oficiales para el desempeño de funciones públicas determinado en el Artículo 234. 7 será de aplicación progresiva de acuerdo a Ley.

No texto já citado de García Linera (2005), em que propunha um sistema de autonomias indígenas e regionais, o analista político e professor considerava a necessidade de que servidores públicos indígenas estejam em todos os níveis do governo na mesma proporção que a população indígena ocupa no total da população boliviana. Já como vice-presidente, em março de 2007, em reunião do grupo Comuna, assume como “impossível” encontrar quadros indígenas capacitados para o Estado. Lamenta que não existam técnicos petroleiros indígenas nem subsecretários em nenhum dos três ministérios mais importantes. Era uma situação comum à que a gestão administrativa se encontrava: não se tratava aqui de falta de definição conceitual, mas de falta de definição na realização das ideias, forçada pelas limitações concretas da realidade social e estatal do pais. De fato, o caráter difuso, contraditório ou com sentido ambivalente não só é interno à nova Constituição, mas, também, próprio do processo político, como fica claro se considerarmos o texto e as intenções do governo em relação à prática de governo, ou à realidade das instituições estatais. 


\section{O REGIME DE AUTONOMIAS}

Outro assunto que queria considerar nos devolve ao Dois. É a contradição principal na política boliviana dos últimos anos, o da autonomia dos departamentos e que se expressou nas ruas, com um referendo em 2006 e nas disputas pelo modo em que um regime respectivo se introduzia na nova Constituição.

A chegada do MAS ao poder configurou um cenário político partido, com dois modelos de país, dois sistemas ideológicos, duas tradições políticas e dois centros geográficos. De todas as divergências presentes no mundo político boliviano, essa apareceu como a mais importante nos primeiros três anos de governo e no processo constituinte. Para o governo, o Estado aparece, pela primeira vez, ocupado pelo povo, que iniciou um processo revolucionário e de descolonização. O “processo de mudanças” dá forma ao que se deu em chamar "Revolução Democrático Cultural”. Do outro lado, nas terras baixas da Meia Lua, conformada pelos departamentos (Estados) de Santa Cruz, Beni, Pando e Tarija no sul, o Estado, hoje, é governado de modo totalitário sob influencia de Hugo Chávez e com um projeto de Estado centralista que não garante a justiça, nem os direitos individuais favorecendo aos indígenas em detrimento de outros cidadãos.

Assim, de um lado, é levantada a bandeira da autonomia, de outro, da Revolução. São dois projetos políticos diferentes que nos levam a ouvir, no leste da Bolívia, sobre regionalismo e nação, de federalismo e liberdade frente ao invasor de ocidente e, na parte ocidental, sobre socialismo, soberania econômica e ingresso das maiorias no Estado, apesar da elite de direita oligárquica latifundiária, racista e cúmplice dos governos neoliberais e ditatoriais que busca impedir as transformações. Na Meia Lua, ouvimos sobre prosperidade empresária, e nas terras altas, sobre a herança indígena e o controle dos recursos naturais. No governo, ouvimos sobre nacionalizações e um projeto popular; do outro lado, sobre populismo e má gestão.

Os dois imaginários dão lugar a duas formas de analisar o Estado Boliviano. Do lado do reclamo autonomista, temos a ideia de um centro oprimindo localidades. Do lado da revolução, o Estado é uma unidade que se encontra desafiada por partes separatistas que ameaçam a integridade do todo. $\mathrm{O}$ que muda são as distintas formas em que, no processo constituinte, as duas partes se combinavam. Em algumas análises, se fala de empate empate catastrófico segundo o vice-presidente - em outras, aparecem as figuras do diálogo, encontro, conflito e divisão. Nas disputas políticas da constituinte, as estratégias iam da crítica ao centro, à crítica das partes como centros opressores das suas partes menores. Do ponto de vista das partes, o centro aparecia também como subordinado a um centro estrangeiro (Venezuela). E, no limite, para o centro de Evo Morales, as partes apareciam como virtuais todos separatistas.

É importante salientar, porém, que na Bolívia os dois projetos formam parte de um mesmo sistema político que faz a autonomia aparecer como contrarrevolução; e a revolução, como contra-autonômica. Os dois projetos são parte de um mesmo mundo político, apesar de aparecerem com línguas diferentes. Na Assembleia Constituinte, essa polaridade aparecia como causa da inviabilidade do fórum constituinte. A resolução e o acordo político que dê 
lugar a um novo Estado não veio no tempo da Assembleia Constituinte, que concluiu sem a participação dos representantes da Meia Lua. O pacto veio depois do pico de máxima violência, quando houve ocupação de instituições do governo nas regiões que ameaçavam com desconhecer o governo, aprovando, também, estatutos autonomistas de modo unilateral; e que, no departamento de Pando, indígenas e camponeses partidários do governo sejam mortos por parte de empregados do governo departamental de Pando. Foi só depois do referendo revocatório e que Morales ganhou com o 67,4\% e aquelas expressões desesperadas de resistência por parte da oposição, que o acordo chegou e o referendo constitucional foi encaminhado.

Na Bolívia, é comum a ideia de que sempre se chega à borda do abismo, mas que no último instante antes de cair aparece uma solução. Essa salvação apareceu quando os dois projetos se encontraram na nova Constituição, demonstrando que, no final, nem pareciam tão incompatíveis. A mudança por parte do governo, que viabilizou a mesa de diálogo com as autoridades dos departamentos da oposição, consistiu na aceitação do projeto de autonomias departamentais que, até então, resistiam incorporando assim, o principal reclamo da oposição autonomista. Mas se o projeto das autonomias foi consagrado e interiorizado pelo governo, também é verdade que o triunfo político foi do governo, e não da oposição, com a aprovação da Constituição e se impondo sobre as regiões, que não conseguiram construir uma alternativa nacional ao governo do MAS. Se o governo aceitava a autonomia, a oposição aceitava que o MAS tivesse sua nova constituição. E esse acordo aconteceu no congresso, entre o MAS e a oposição que, no ato de introduzir modificações ao texto e aprová-lo, se desfazia como força política unificada que tinha combatido ao governo na Assembleia Constituinte e no parlamento como uma só.

$\mathrm{Na}$ campanha pela aprovação da nova Constituição, o governo defendia a implementação das autonomias, apesar de que, no referendo autonômico de 2006, Evo Morales tinha se manifestado contra, dando lugar a um resultado que dividiu o país em dois: a Meia Lua a favor da autonomia; Ocidente contra. Só depois da promulgação da nova Carta Magna, o regime autonômico começou a ser pensado como proposta para todo o país.

Por outra parte, a estratégia do governo na disputa com Oriente, já desde a Assembleia Constituinte, era o da potencialização da autonomia indígena apresentada como contraposta ao "centralismo" das capitais de departamentos, governados pelos setores da oposição, e que defendiam o projeto das autonomias departamentais. $\mathrm{O}$ ordenamento territorial do Estado Plurinacional defendido pelo MAS baseia-se no desenvolvimento de autonomias em distintos níveis que desfaçam "para dentro" o poder que os departamentos ganhavam do poder central. É a partir das autonomias indígenas, também, que as nações e povos desenvolveriam suas economias, línguas, culturas e sistemas políticos, justiça, etc, e que se integrariam no Estado Plurinacional. No tex to aprovado, se inclui um regime de autonomias com a mesma hierarquia, que mostra a negociação e a resolução equilibrada entre autonomia indígena, departamental e nível central, selando uma resolução que priorizou a complementaridade dissolvendo a oposição entre o Dois, próprio do universo político boliviano: 
Artículo 272. La autonomía implica la elección directa de sus autoridades por las ciudadanas y los ciudadanos, la administración de sus recursos económicos, y el ejercicio de las facultades legislativa, reglamentaria, fiscalizadora y ejecutiva, por sus órganos del gobierno autónomo en el ámbito de su jurisdicción y competencias y atribuciones.

Artículo 276. Las entidades territoriales autónomas no estarán subordinadas entre ellas y tendrán igual rango constitucional.

A mão da oposição no texto do MAS, no entanto, se ocupou em limitar o alcance da autonomia indígena ao mesmo tempo em que buscava fortalecer o nível departamental. Estes cortes permitiram manter algo do projeto inicial das organizações indígenas, mas tiraram tudo o que do ponto de vista do Estado estabelecido, era intolerável. A oposição não conseguiu impor a sua proposta, na qual os territórios indígenas eram definidos pelo departamento. Mas conseguiu limitar a representação direta dos povos, se estabeleceu que as autonomias não pudessem modificar limites territoriais e que devessem se adaptar à forma atual dos municípios ou Territórios Comunitários de Origem — TCO, titulados desde a década de 90. Tampouco se deu forma às exigências mais radicais dos grupos indígenas que queriam o controle dos recursos naturais nos seus territórios, ou seu exclusivo; mas isto, sem que tivesse intervindo a oposição, a partir das diferenças que apareceram no delineamento do projeto por parte do próprio MAS. Deve-se mencionar que muito da resistência às autonomias indígenas vem dos sindicatos campesinos afins ao MAS, especialmente quando estes controlam os municípios onde a autonomia indígena estabeleceria outro tipo de governo. Se bem que esses sindicatos acolhem cada vez mais a identidade indígena, em muitas localidades continua sendo forte a oposição entre autoridades originárias e sindicais, às vezes como simples disputa de poder que se expressa na oposição entre a política da cultura vs. a política da classe.

A ambiguidade no regime de autonomias é analisada por Albert Noguera (2008). Mesmo depois que o governo decidisse abraçar a introdução das autonomias, a Constituição continuou sem se definir a favor de um modelo claro sobre esse assunto. Se este autor assinala que o texto é pioneiro e vanguardista no reconhecimento do caráter Plurinacional do Estado e na participação dos diferentes sujeitos coletivos sobre o tema de autonomias, considera que "tem como objetivo dar uma aparência de Estado autonômico ou ser mais uma declaração de fachada, para intentar satisfazer as demandas de Santa Cruz e dos distritos do Oriente”. Segundo Albert Noguera, no texto, não há uma aproximação técnica real ao modelo espanhol de organização territorial autonômica em que se inspirou e, "apesar de sua autodenominação no art. 1 1ํㅡㅇ o modelo territorial boliviano não é um Estado autonômico, mas um modelo de Estado simples e unitário [...] o novo projeto de Constituição boliviana leva o centralismo ao limite do possível, mas não o supera”. Um elemento que, para Noguera, demonstra isso é a "cláusula residual” pela qual as constituições prevêem mecanismos para cobrir vazios de destinações de competência. Se, em casos como Itália e Espanha, na omissão, se favorece o nível intermediário de autonomia, na Bolívia, toda competência não incluída será atribuída ao nível central do Estado. Apesar da análise de Noguera sendo prévia ao último acordo com a oposição, este ponto permaneceu no texto depois do pacto político pelo que a análise geral continua sendo válida. 
Apesar de ter sido incluído na nova Constituição o mais amplo catálogo distribuidor de competências do mundo, muito se definirá na negociação e na luta política futura das instâncias autonômicas com o poder central. Ainda não se pode prever o destino que estes processos tomarão. As indefinições relativas à autonomia indígena abrem uma série de possibilidades que também se vinculam às diferentes estratégias das organizações. Em alguns casos, tratar-se-á do intento de recomposição de territórios ancestrais; em outros, o processo se apoiará nas estruturas municipais já existentes. Em algumas regiões, os sindicatos campesinos impulsionarão as autonomias e, em outras, serão os que se oponham a esta nova forma de poder territorial, como continuação da disputa entre originários e campesinos que vimos aparecer na definição do povo boliviano.

\section{Conclusão}

Como vimos, a Bolívia aparece marcada pela ambiguidade e também por uma divisão em dois que ora provoca fraturas, ora se resolve com a complementação das diferenças. No caso da nova Constituição, as "duas bolívias" entraram no novo texto, conjugadas pela proposta do pluralismo. É uma resposta que não apaga nem tenta homogeneizar as diferenças, mas a mantém de forma intensiva num Estado Unitário que, ao mesmo tempo, é Plurinacional e descentralizado. Na nova Constituição, assim, vemos marcas de um projeto que surge do centro e que fala de revolução, e de outro que vem das regiões exigindo autonomia. As diferentes direções incluídas deram como resultado um texto com conflito no seu interior. A resolução é plural, é unitária e é, também, autonomista, uma complexa trama de controles, avanços e limites, que deixa a resolução para a política em que as tensões das "duas bolívias" testaram o pluralismo e a autonomia na vida política dos próximos tempos. Será dando curso ou freando, no congresso ou nas comunidades, onde os bolivianos tentaram definir, nas disputas políticas que vinham de antes do processo constituinte e continuaram depois, a resolução ou continuidade da divisão, ou das suas possíveis alternativas.

E, talvez, a solução seja manter a ambiguidade e a ambivalência. Isso tem a ver com a força da oposição para impor controles, mas tem a ver, também, com a busca de consenso entre o governo e a oposição e entre as partes que formam o MAS. Devemos acrescentar, porém, que a indefinição responde, às vezes, à difícil tarefa de traduzir para o código estatal as reivindicações sociais e instituições indígenas não estatais. Tudo isso deu lugar a uma Constituição irregular, com tensões e "de transição", segundo os movimentos sociais na base do MAS, e algumas autoridades. Como vimos, o texto inclui definições em sentidos diferentes no assunto da Justiça; uma definição postergada pela realidade estatal no caso da incorporação das línguas ao aparelho de governo; falta de claridade e multipli-cidade de sentidos na definição do caráter plurinacional; e amplitude e redundância no que diz respeito à economia e à definição do sujeito chave da nova ordem constitucional. A mesma indefinição e flexibilidade aparece quando nos perguntamos sobre a identidade do governo e sobre o caráter do indígena no atual processo político.

Pensando neste processo constituinte particular, também, surge a pergunta se na política é pensável uma situação mais folgada e sem conflito, em que um projeto político 
possa ser definido de modo claro; ou se acaso a mistura de componentes, a ambiguidade e a indefinição é, antes bem, uma característica própria de todo processo político, em alguma medida, sempre presentes na hora de definir as bases de um Estado e o sentido das políticas de um governo. O caso estudado nos leva a pensar que a hipótese da política sem conflito e sem resolução, em algum ponto, aberta, é difícil de encontrar na realidade.

\section{REFERÊNCIAS BIBLIOGRÁFICAS}

ALBÓ, Xavier. Las circunscripciones especiales indígenas. La Razón, 5 de abril 2009. Disponível em: <http://www.la-razon.com/versiones/20090405_006688/nota_246_790093.htm>.

BORTH, Carlos. 40 días que conmovieron a Bolivia y un pacto político forzado. Mimeo, 2008.

CONSTITUCIÓN POLÍTICA DEL ESTADO. Estado Plurinacional de Bolivia. Disponible en: <http://www.abi.bo/abi/banner_240_240/nueva_cpe.pdf>.

ESCÓBAR, Filemón. De la revolución al Pachakuti. El aprendizaje del respeto recíproco entre blancos e indianos. La Paz: Garzazul, 2008.

ESTERMANN, Josef Filosofía andina. Estudio intercultural de la sabiduría autóctona andina. Quito: Abya Ayala, 1995.

FERNÁNDEZ, Albert Noguera. Plurinacionalidad y autonomías. Comentarios entorno al nuevo proyecto de Constitución boliviana. Revista Española de Derecho Constitucional, n. 84, p. 147-177, sep./dic. 2008.

KYMPLICKA, Will. Ciudadanía multicultural. Barcelona: Paidós, 1996.

LINERA, Álvaro García. Estado multinacional. Una propuesta democrática y pluralista para la extinción de la exclusión de las naciones indias. La Paz: Malatesta, 2005.

; GUTIÉRREZ, Raquel; PRADA, Raúl; TAPIA, Luis. El retorno de la Bolivia Plebeya. La Paz: Muela del Diablo, 2000.

; TAPIA Mealla, Luis; ALCOREZA, Raúl Prada. La transformación pluralista del Estado. La Paz: La Muela del Diablo, 2007.

MORALES, Teresa. et al. Organización económica del Estado en la nueva Constitución Política del Estado. La Paz: Enlace, Oxfam, 2008.

PRADA, Raúl. Subversiones indígenas. La Paz: CLACSO/Muela del Diablo, 2008. . Una constitución de transición. Revista Archipiélago, abr./may. 2008.

RADA, Andrés Soliz. 2009. Cossío, el gonismo y el MAS. La Prensa, 18 de janeiro de 2009. Disponível em: <http://www.laprensa.com.bo/noticias/18-01-09/18_01_09_opin2.php>.

REINAGA, Fausto. La revolución india. La Paz: Fund. Amaútica F. Reinaga, 2001.

SIVAK, Martín. Jefazo. Buenos Aires: Sudamericana, 2008.

TAPIA, Luis. Condición multisocietal. Multiculturalidad, pluralismo, modernidad. La Paz: CIDES-UMSA/Muela del Diablo, 2002.

TEMPLE, Dominique. La dialéctica del Don. Ensayo sobre la oikonomía de las comunidades indígenas. La Paz: Hisbol, 1995. 